\title{
Os pilotos de caça da Grande Guerra de 1914-18 e o retorno dos embates cavalheirescos: breves apontamentos sobre a autobiografia do Barão Vermelho
}

Delmo de Oliveira Arguelhes ${ }^{1}$

\begin{abstract}
Como os rituais de um velho mundo cercavam as realizações do novo, o estado de espírito era de melancolia e pesar, acompanhado por uma trêmula e ansiosa excitação. Voar sempre possuiu um enorme simbolismo para o homem; durante a guerra esse simbolismo se intensificou. $O$ ás da aviação era objeto de ilimitada inveja entre os soldados da infantaria, atolados na lama e aparentemente indefesos. [...] Os "cavaleiros do céu" estavam envolvidos num conflito em que o esforço individual ainda contava, em que as noções românticas de honra, glória, heroísmo e bravura ainda se mantinham intactas. No ar, a guerra ainda tinha significado.
\end{abstract}

Modris Eksteins, A sagração da primavera.

\section{Resumo:}

O presente artigo inventaria procedimentos interpretativos no campo da história das idéias acerca da autobiografia do piloto alemão Manfred von Richthofen (1892-1918), com fonte histórica fundamentada nas concepções de heroísmo, honra e cavalheirismo dos pilotos de caça na Grande Guerra de 19141918.

Palavras-chave: História das idéias. História da $1^{\text {a }}$ Guerra Mundial. Narrativas auto-biográficas.

\footnotetext{
${ }^{1}$ Doutor em História das Idéias (UnB, 2008), mestre em História das Relações Internacionais (UnB, 1996), licenciado em História (UniCEUB - DF, 1991). Professor dos cursos de História e Relações Internacionais do UniCEUB; professor do curso de Relações Internacionais da UniEURO - DF.
} 


\section{Introdução}

A assertiva citada demonstra um ponto pacífico acerca da Grande Guerra: que os pilotos de caça ${ }^{2}$ de 1914-18 eram os herdeiros da tradição cavalheiresca medieval. Tanto os escritos da época, como os subseqüentes aceitam esse fato como inconteste.

A Grande Guerra inaugurou um novo estilo de luta, a guerra total. Não foram apenas as forças armadas que se defrontaram ao longo da contenda, mas populações inteiras. O Estado, a sociedade e a produção industrial voltaram-se, exclusivamente, para sustentar o esforço de guerra. A junção dos meios nacionais com os avanços tecnológicos produziu cifras ainda hoje aterradoras: índices de baixas de 350\% nos exércitos engajados desde o princípio da luta; 20 milhões de seres humanos, entre militares e civis, mortos até novembro de 1918.

O assassinato do arquiduque Franz Ferdinand, herdeiro do trono austrohúngaro, em 28 de junho de 1914, forneceu à monarquia dual o pretexto para realizar uma expedição punitiva contra a Sérvia. Em pouco mais de um mês, entre o $1^{\circ}$ e o $4^{\circ}$ dia do mês de agosto, as principais potências européias embarcaram numa guerra generalizada. As expectativas de que a guerra seria curta, edificante e até divertida terminaram com o início dos combates nas trincheiras. Apenas na batalha do Somme, entre julho e novembro de 1916, mais de 1.600.000 homens pereceram, sem qualquer resultado decisivo para os dois lados em conflito.

Nos primórdios da Grande Guerra, as aeronaves eram utilizadas apenas para observação dos movimentos adversários. Na medida em que o conflito evoluiu, foram construídos aviões especializados para carregar e lançar bombas sobre os mais diversos alvos, inclusive civis. Desse momento em diante, tornou-se tão importante quanto a observação e o bombardeio, o abate dos aviões inimigos. Essa necessidade fez surgir o avião de caça. O primeiro modelo de caça realmente

\footnotetext{
${ }^{2}$ No jargão militar, avião de caça é uma aeronave especializada em combater outros aviões, sendo peça fundamental para a obtenção de superioridade aérea. O combate aproximado entre aviões de caça é denominado dogfight, devido às curvas, ascensões e mergulhos executados pelos combatentes.
} 
eficiente, dotado de uma metralhadora sincronizada com a hélice ${ }^{3}$ - copiado em seguida por ingleses e franceses - foi o Fokker Eindecker (monoplano), projetado por um engenheiro aeronáutico holandês a serviço dos alemães: Anthony Fokker.

Entre 1915 e 1916, diversos pilotos começaram a se digladiar na frente ocidental, iniciando a assim chamada Era dos Ases. ${ }^{4}$ Os ases da guerra tornaram-se famosos, com grande cobertura pela imprensa da época. Adolphe Pégoud, Roland Garros (franceses), Lanoe Hawker (britânico), Oswald Boelcke e Max Immelmann (alemães) foram os primeiros a se destacarem, abatendo um número considerável de oponentes.

Boelcke - morto num acidente aéreo em 1916, com 40 vitórias confirmadas - é considerado o grande teórico do combate aéreo. Desenvolveu um manual de conduta para os pilotos germânicos, que, na prática, consistia em assegurar o máximo de vantagens no momento do ataque. As lições de combate aéreo desse manual eram semelhantes às regras de caça esportiva de animais selvagens: o caçador tinha que ficar à espreita, aguardar uma boa posição de tiro e acertar o alvo a curta distância. Do outro lado, o piloto caçado deveria executar uma série de manobras para se evadir da linha de tiro, num primeiro momento, e tentar enquadrar e acertar o oponente.

Uma das características das aeronaves militares de 1914-18 era o uso extensivo de cores chamativas - em contraposição às tendências seguintes de usar camuflagem. Cada esquadrilha possuía um esquema próprio de cores. Os principais pilotos usavam cores e marcas específicas: Ernst Udet (alemão com 62 vitórias) pilotava um avião vermelho com o nome da esposa, Lo, seguido de uma exclamação; Eduard Ritter von Schleich (alemão, 35 vitórias) era conhecido pela alcunha de Cavaleiro Negro pelo fato de usar uma aeronave dessa cor; Charles Nungesser (francês, 45 vitórias) utilizava como insígnia um coração negro, dentro do qual constava uma caveira em cima de dois ossos cruzados, além de um caixão e velas;

\footnotetext{
${ }^{3}$ Os primeiros pilotos logo perceberam, pela experiência de combate, a necessidade de instalar uma ou duas metralhadoras que disparassem pela frente do avião, para facilitar a mira. O grande obstáculo para isso era a hélice. O mecanismo de sincronia interrompia as rajadas no momento em que a hélice estava na linha de tiro; ou seja, graças a tal dispositivo as metralhadoras atiravam nos intervalos dos propelentes.

${ }^{4} \mathrm{Na}$ aviação militar, a designação ás refere-se ao piloto que abateu, pelo menos, cinco aeronaves.
} 
Georges Guynemer (francês, 53 vitórias) usava a cor branca e a inscrição Vieux Charles. Durante os combates aéreos, os oponentes mais notórios reconheciam-se mutuamente. Um dos dogfights mais conhecidos da guerra foi entre Udet e Guynemer, em que o narrador fez questão de enfatizar a forma honrada da disputa. Ao perceber que as metralhadoras do piloto germânico estavam travadas, Guynemer abandonou o combate para não se aproveitar de um adversário em dificuldades (UDET, 1937, p. 58-60).

No ar, a guerra era travada de modo "limpo". Os pilotos ficavam estacionados em aeródromos na retaguarda, ora instalados em barracas, ora em castelos requisitados pelas forças ocupantes. De qualquer modo, tinham mais conforto do que os soldados nas trincheiras. Nos dogfights, a habilidade e a destreza eram os fatores que levavam à vitória, pelo menos na visão do senso comum. Nos relatos sobre a guerra, os pilotos faziam diversas referências à honra e ao heroísmo. Mostravam também respeito pelos valorosos adversários. Durante a guerra, os pilotos capturados eram homenageados pelo esquadrão responsável pelo abate com uma grande festa. No dia seguinte, o prisioneiro era encaminhado para um campo de detenção. Os jornais da época noticiavam as vitórias dos ases, mesmo que fossem do lado adversário.

O aprendiz mais notório de Boelcke foi também o piloto mais famoso da guerra: Manfred Freiherr von Richthofen, morto em combate em 21 de abril de 1918, com 80 vitórias confirmadas. O avião mais conhecido pilotado por ele era um Fokker Dreidecker (triplano) vermelho com o leme branco e ganhou o cognome de Barão Vermelho. Richthofen era oficial de cavalaria no início do conflito, tendo se transferido em 1915 para o serviço aéreo. Em 1916, passou a integrar a Jasta $2,{ }^{5}$ sob o comando de Boelcke. Dentre os seus primeiros feitos, incluiu-se a morte do ás britânico Hawker - $11^{\text {a }}$ vitória, no dia 23 de novembro de 1916 (KILDUFF, 1993, p. 224).

Após a morte de Boelcke, Richthofen foi indicado para comandar a Jasta 11. Aperfeiçoando a idéia do mestre, em 1917, quando já havia alcançado grande reconhecimento público - pois, nesse momento, seu escore constava mais de 50

\footnotetext{
${ }^{5}$ Jasta, abreviatura de Jagdstalffen (esquadrilha de caça) era a formação básica de aviões, de 12 a 15 aparelhos, preconizada por Boelcke para garantir a superioridade aérea no campo de combate.
} 
adversários abatidos - reuniu mais três Jastas sob suas ordens: a $4^{\mathrm{a}}$, a $6^{\mathrm{a}}$ e a $10^{\mathrm{a}}$. Essa grande formação, denominada oficialmente Jagdgeschwader 1 (esquadrão de caça), ou JG 1, ficou conhecida popularmente como o Circo Voador. Dentre os ases que compunham o circo, estava um dos irmãos de Manfred - Lothar -, que sobreviveu à guerra com 40 vitórias.

Em julho de 1917 - convalescendo de um ferimento no crânio, resultado de um combate aéreo não muito bem sucedido - Richthofen finalizou com o auxílio de uma estenógrafa e publicou suas memórias: Der rote Kampfflieger (O piloto de combate vermelho). Lido com grande interesse pelo público alemão, o rittmeister (capitão de cavalaria) recebeu um grande volume de cartas dos leitores. Meses após a publicação da autobiografia, o barão faleceu, sobrevoando a frente ocidental, tendo sido enterrado com plenas honras militares por um de seus adversários, a Força Expedicionária Australiana. Somente em 1925, o corpo de von Richthofen foi transladado para a Alemanha.

Entre algumas pistas relevantes para estudar a tradição cavalheiresca reclamada pelos ases (ou pelos seus intérpretes), incluem-se as autobiografias. Tentaremos assim realizar algumas observações pontuais a partir de algumas passagens de Der rote Kampfflieger, de Manfred von Richthofen. Em suma, o que se pretende é tão somente explorar as possibilidades analíticas do documento proposto no âmbito da história das idéias. Antes, no entanto, é deveras propício levantar algumas considerações teóricas.

Ao tratar de transmissão de tradições entre a cavalaria medieval e os pilotos de caça, deve-se conceituar o que é tradição. Segundo Hans-Georg Gadamer, (1997, p. 373) “é essencialmente conservação e como tal sempre está atuante nas mudanças históricas”. Ou seja, tanto na manutenção das engrenagens sociais quanto nas mudanças, a tradição está presente. $\mathrm{O}$ indivíduo está sujeito à autoridade da tradição desde o seu nascimento. Pois não se encaixa na sociedade como uma tabula rasa, mas inserido na tradição. Obviamente, a tradição não é algo estanque, ela é reinvestida de significados ao longo das gerações. "Os costumes são adotados livremente, mas não são criados nem fundados em uma validade por um livre discernimento.” Daí, Gadamer (1997, p. 372) advoga que a característica da tradição é “ter validade sem precisar de fundamentação". 
Quando as experiências abrem novos horizontes de expectativa, as tradições têm um papel importante na construção de um novo referencial. ${ }^{6}$ A eclosão Grande Guerra abriu as expectativas para um futuro glorioso e heróico para os combatentes e para a nação. Seria o momento regenerador de uma sociedade européia conformista e a vitória da civilização contra a barbárie - fossem esses bárbaros eslavos, germânicos, gauleses ou britânicos. No entanto, a experiência das trincheiras mostrou acima de tudo o horror da guerra. Os soldados estavam expostos à artilharia pesada, metralhadoras, gases químicos, ratos, piolhos e pulgas. Os civis enfrentaram a carestia, impostos excessivos, a dor da perda de entes queridos e, nas regiões envolvidas nos combates, estupros, saques, bombas e represálias dos ocupantes. Num conflito que exigia toda a participação das populações, manter o moral elevado era uma preocupação constante dos estados-maiores. A propaganda de guerra foi intensa e a imagem dos ases da aviação teve um grande papel na manutenção do apoio à guerra.

Sendo a autobiografia a emergência do discurso do indivíduo, evocando a memória, torna-se importante questionar o que é o indivíduo. Tratando dessa questão, Paul Ricoeur o concebe em duas dimensões: uma material, exemplar único da espécie, e outra moral, um ser independente e autoconsciente. O elemento chave da análise de Ricoeur é a linguagem; através dela o indivíduo reconhece a si mesmo, ordena o discurso e, nesse discurso, fala a si mesmo (RICOEUR, 1988, p. 65-66). A pragmática, que cuida das condições de interlocução construídas na língua, destaca o indivíduo falante. Os pronomes designam os seres de modo relativo. Os indivíduos falantes localizam-se entre eu e $t u$. Já o nome próprio é mais específico. Situa o indivíduo na sociedade e no tempo; portanto o localiza na História (RICOEUR, 1988, p. 71-74).

\footnotetext{
${ }^{6}$ As categorias espaço da experiência e horizonte de expectativas, desenvolvidas pelo historiador Reinhart Koselleck, são categorias apropriadas para a cognição da história, na medida em que incorporam o passado e o futuro do presente histórico. A experiência é o "passado presente, cujos eventos foram incorporados [de um ou outro modo] e podem ser relembrados". A expectativa é a projeção do futuro, do que ainda não foi, daí o seu locus, o horizonte, a linha aparente jamais atingida e sempre movediça. As experiências alimentam as expectativas, mas não as determinam; do outro lado, o inesperado cria novas experiências. Essas categorias, que não se relacionam estática e diretamente, estão povoando qualquer momento da história humana (KOSELLECK, 2006, p. 305-327).
} 
Mesmo pensando o indivíduo, não podemos ignorar a interação com a sociedade, pois o ser humano estabelece-se enquanto tal em contato com o restante da espécie. O humano, privado do convívio com o outro, desumaniza-se. Utilizando exemplos literários, Tarzan e Mowgli estavam menos próximos da humanidade do que dos macacos e lobos. Ao pensar o ser humano, Hannah Arendt situou as atividades do indivíduo em três níveis: labour, work e action. O labour e o work - relação com a natureza e a realização de monumentos de cultura - foram situados pela filósofa na esfera privada. A action - convivência política com os iguais, localizada na esfera pública - é uma ação auto-alimentada. Estabelece-se e mantém-se na memória social pelos relatos acerca dela. A honra e a virtude guerreira individuais dependem principalmente do reconhecimento social, tanto no seu estabelecimento quanto na sua manutenção.

Outra questão, também de grande relevância do indivíduo, é que ele não é um todo unitário. Freud e Lacan nos ensinam que o sujeito possui múltiplas facetas. Daí a representação lacaniana do sujeito como um 'S' barrado (S). O ich (eu) (a) mantém uma relação especular com o pequeno outro (a') e o grande outro (A). Essa relação estabelece-se desde a mais tenra idade, durante o estádio do espelho, quando a criança é confrontada com a própria imagem especular na companhia de adultos. De modo extremamente simplificado, o eu (a) passa a ter como referências a sua imagem especular (a') e o seu devir, o adulto (A). O sujeito - que Lacan chama a atenção que não é total - sempre tem como referência os outros. Com esses outros, ele constrói sua identidade (LACAN, 1985, p. 307, 1998, p. 96-103).

Quanto à relação do indivíduo com a massa, Freud observou que "na reunião dos indivíduos na massa, desaparecem todas as inibições individuais e, como relíquias de uma era mais primitiva, são despertados para procurar uma livre satisfação pulsional” (FREUD apud GAY, 1989, p. 126). Freud identificou os laços de união do indivíduo com a multidão a partir de dois elementos fundamentais: o amor e o ódio, o que explica certas dimensões da Grande Guerra. Obviamente, apesar dessa ligação social, seja em classes, no esporte ou em qualquer outra divisão proposta, não podemos pensar o indivíduo a partir dela; Freud percebeu que "todo indivíduo é uma parte composta por muitas multidões, ligado de diversas maneiras através de identificações, e que construiu o seu ego ideal a partir dos modelos mais variados" (GAY, 1989, p. 127). Daí vem a identificação com o outro, tão necessária ao indivíduo. 
Ao longo do percurso, devemos estabelecer uma relação de aproximação e distanciamento em relação ao objeto. A aproximação é necessária para não perder de vista o questionamento inicial. Sem ela, corre-se o risco de construir uma imensa paráfrase do objeto. Por outro lado, o distanciamento é necessário, sob o risco de silenciar a fonte; assim, o pensamento do autor ficaria encoberto por nossas projeções. Segundo Jean Starobinski (1995, p. 141), a tarefa da interpretação é justamente construir uma passagem entre o texto e a atualidade. Essa tarefa só é possível quando o intérprete opera um aproximar-e-distanciar do objeto.

"Como se pode proteger um texto previamente frente a mal-entendidos?” (GADAMER 1997, p. 357). Essa questão levantada por Gadamer é crucial para o desenvolvimento de nossa proposição. Sempre que qualquer leitor entra em contato com um texto, ele projeta sobre o mesmo, os seus preconceitos. ${ }^{7}$ O processo de aproximação e distanciamento do objeto passa pelo reconhecimento dos preconceitos do próprio intérprete, mas esse reconhecer não implica em eliminá-los, mesmo porque isso não seria possível. Esse reconhecimento torna possível uma interpretação mais coerente. Devemos sublinhar também que não é possível tecer a interpretação definitiva de qualquer texto, pois isso implicaria, em última instância, compreender o texto tanto quanto, ou mais do que o próprio autor.

Esse posicionamento nos conduziria às intenções do autor. Qual seria o real significado que o escritor desejou urdir com essa ou aquela construção textual específica? O que o autor realmente quis dizer? Dado que os sentidos de um texto sempre superam as intenções autorais; que a leitura de qualquer texto nunca é um ato passivo, mas produtivo; e, em cada época e lugar, leitores com experiências diversas e conceitos diversos vão produzir significados, além de novos, diversos, podemos afirmar que as intenções do autor estarão sempre

\footnotetext{
${ }^{7}$ Segundo Gadamer (1997, p. 354-368), o preconceito, ou juízo prévio, nada mais é do que um juízo emitido antes da análise do objeto, podendo estar correto ou não. É aquilo que insere o indivíduo na realidade histórica, sendo, portanto um fenômeno que, além de não poder ser evitado, constitui a própria realidade histórica do sujeito. A conceitualização do termo preconceito como algo negativo remonta ao pensamento iluminista. Os iluministas rejeitavam qualquer fonte de saber que não fosse baseada na razão, daí Gadamer afirma que os iluministas desenvolveram, contraditoriamente, um preconceito contra os preconceitos. Continuaram presos àquilo que desejavam abolir.
} 
inacessíveis a uma apreensão totalizante e unívoca. "Basta dizer que, quando se logra compreender, compreende-se de um modo diferente" (GADAMER, 1997, p. 392).

É importante frisar também que esses apontamentos não nos conduzem a uma abordagem sem qualquer parâmetro. No limite, esse aspecto poderia levar a um relativismo total. No outro extremo, ignorar essas questões seria admitir a existência de uma cognição objetiva da história. Por esses motivos, a construção de um método analítico que atenda às demandas do objeto é uma condição sine qua non. As informações obtidas do estudo das fontes precisam ser confrontadas com as mesmas. Nesse terreno movediço, se existe algum ponto de apoio, este é o documento. Não existe o método correto para a análise documental. Existem procedimentos. Estes são construídos como demanda do documento em si e do olhar deitado sobre o objeto.

O estudo do objeto em questão poderá ser feito através de diversos caminhos. Longe de pretender alguma aproximação definitiva, essas abordagens complementam-se ao revelarem múltiplas facetas do texto. Poderemos começar com a análise do vocabulário empregado pelo autor. Os significados (conceitos) ligam-se dinamicamente aos significantes (palavras). Contudo, enquanto os significantes são mais perenes, os significados variam sincrônica e diacronicamente. Conceitos atribuídos a termos como pátria, revolução e democracia, por exemplo, variam de sociedade para sociedade ao longo do tempo e, também, ao mesmo tempo. Essa variação não ocorre de modo aleatório, mas está ligada intimamente à prática histórica. As práticas modificam o vocabulário, e este modifica as percepções de mundo. Em suma, trata-se de uma abordagem histórica conceitual. ${ }^{8}$ A não observância dos conceitos variáveis leva fatalmente a uma explicação histórica anacrônica. Portanto, esse viés possibilita perceber como e quais conceitos Richthofen empregou na elaboração do texto e se modificou ou reinterpretou significados.

Agregado à questão conceitual, situa-se o vocabulário da época. A novidade da aviação de caça em 1914-18 criou novos conceitos associados à nova

\footnotetext{
${ }^{8}$ Para uma discussão mais aprofundada sobre a história conceitual (Begriffsgeschichte), ver Koselleck (1991, p. 134-146; 2006, p. 73-91).
} 
prática como ás, dogfight ou vitórias aéreas, dentre outros. Junto com os pilotos, surgiu um paradigma lingüístico específico. ${ }^{9}$ A confrontação do rote Kampfflieger com os demais documentos - nos quais podemos incluir outros relatos, jornais, dicionários e enciclopédias da época - será importante para fazer emergirem as regras do jogo lingüístico praticado por Richthofen e seus pares. Assim, poderemos delinear o que o autor poderia ou não pensar e exprimir. Em épocas turbulentas, quando acontecem mudanças radicais, como foi o caso da Grande Guerra, o vocabulário sofre diversas alterações e discordâncias. É preciso ficar atento às mudanças sutis operadas dentro da linguagem.

A relação texto/contexto também é fundamental. Empregamos contexto no sentido lato, como o que fornece a base significativa para a compreensão textual. Há uma relação dialógica entre ambos. O texto não pode ser separado do contexto, sob o risco de se submeter a interpretações anacrônicas. Por outro lado, leituras cuidadosas enriquecem e até mesmo reconstroem o contexto. Finalmente, o contexto apresenta-se ao historiador também como uma forma textualizada.

A recepção do público leitor também deve ser levada em consideração, pois está imbricada nessa rede sutil. Não se trata simplesmente de um mecanismo de causas e conseqüências.

A relação entre literatura e leitor possui implicações tanto estéticas quanto históricas. A implicação estética reside no fato de já a recepção primária de uma obra pelo leitor encerrar

\footnotetext{
${ }^{9}$ John Pocock concebe paradigmas lingüísticos - a partir das teorizações sobre a ciência de Thomas Kuhn - que servem de contexto para os escritos, declarações e discursos políticos. Portanto, dentro de uma linguagem de uma determinada época e lugar, a mesma contém regras - e conceitos - do que e como escrever e falar, e, por extensão, do que e como se pensar. Mas se "a linguagem determina o que nela pode ser dito, [...] ela [também] pode ser modificada pelo que nela é dito" (2003, p. 64). Grupos restritos também possuem paradigmas próprios dentro de uma linguagem mais abrangente. Ao contrário da explanação kuhniana, múltiplos paradigmas lingüísticos podem coexistir simultaneamente. Apesar da ênfase no estudo das nuances da linguagem, Pocock sublinha também a importância da experiência, da práxis social, influindo no vocabulário político e vice-versa. Os paradigmas lingüísticos também não são enclausurados pelos grupos praticantes. Eles podem migrar de um segmento para outro. Numa sociedade complexa utiliza-se uma miríade de linguagens específicas, através de múltiplos modos retóricos. "Esta história pode ser definida como uma história das mudanças no emprego dos paradigmas, na exploração dos paradigmas e no emprego de paradigmas para a exploração dos paradigmas" (1971, p. 23). Para maiores detalhes, ver Pocock (1971, p. 3-41; 2003, p. 63-82).
} 
uma avaliação de seu valor estético, pela comparação com outras obras já lidas. A implicação histórica manifesta-se na possibilidade de, numa cadeia de recepções, a compreensão dos primeiros leitores ter continuidade e enriquecer-se de geração em geração, decidindo, assim, o próprio significado histórico de uma obra e tornando visível sua qualidade estética. (JAUSS, 1994, p. 23).

Nesses termos, Hans-Robert Jauss trata da estética da recepção do texto, enfatizando, dentre outros aspectos, os efeitos da obra na sociedade pelos aspectos sincrônicos e diacrônicos.

O estudo da obra deve-se estender à análise das gerações que a leram e interpretaram. Jauss enfatiza assim o impacto do texto. $\mathrm{O}$ autor, ao concebê-lo, tenta idealizar o tipo de leitor que pretende atingir e, às vezes, esse aspecto emerge através de uma leitura cuidadosa.

O último aspecto é a apreciação crítica da autobiografia como gênero literário. Mikhail Bakhtin, ao ocupar-se das biografias e autobiografias, afirmou que não existe uma demarcação nítida entre esses dois gêneros; pois na biografia, muitas vezes o autor quase que confunde seus próprios valores com o herói da narrativa.

Aqui a personagem e o narrador podem facilmente intercambiar posições: seja eu a começar narrando sobre o outro, que me é íntimo, com quem vivo uma só vida axiológica na família, na nação, na sociedade humana, no mundo, ou o outro a narrar a meu respeito, de qualquer forma eu me entrelaço com a narração nos mesmos tons, na mesma configuração formal que ele. [...] Ao narrar sobre minha vida cujas personagens são os outros para mim, passo a passo eu me entrelaço em sua estrutura formal da vida (não sou o herói da minha vida, mas tomo parte nela), coloco-me na condição de personagem, abranjo a mim mesmo com minha narração; as formas de percepção axiológica dos outros se transferem para mim onde sou solidário com eles. É assim que o narrador ser torna personagem. (BAKHTIN, 2003, p. 141).

Bakhtin também concebe dois tipos básicos de narrativa biográfica: a aventura-heróica e a sociodoméstica. Apenas o primeiro nos interessa. O modelo aventureiro-heróico pode subdividir-se em três aspectos relativos ao desejo do personagem: 1) a vontade de ser herói; 2) a vontade de ser amado e 3) a vontade 
de superar a fabulação da vida. Em suma, essas vontades podem ser condensadas resumidamente no reconhecimento social e na honra do protagonista (BAKHTIN, 2003, p. 143).

Assim, a autobiografia mostra-se muito mais densa do que uma simples rememoração ou do que o relato linear de algum personagem relevante e/ou interessante. Além dos tipos intercambiáveis (o eu e os outros), a própria figura do eu - que não é monolítico, lembrando o sujeito partido lacaniano - na narrativa ele é ainda mais fragmentado. Ao descrever-se numa biografia, o sujeito escolhe, consciente ou inconscientemente, que aspectos deve ou não mostrar da própria personalidade, assim como também escolhe os eventos a serem narrados. Esse eu é mais um outro, dentre diversos outros.

Na Alemanha, foram publicadas duas edições de Der rote Kampfflieger: a primeira em 1917, quando Richthofen ainda estava vivo; e a segunda, em 1933, acrescida com vários adendos. A edição de 1933, que utilizaremos aqui, possui um prefácio assinado pelo então ministro de aviação do Reich Hermann Göring, terceiro e último comandante da JG 1 em 1918; também foram incluídos capítulos escritos pelos irmãos de Richthofen, Lothar e Bolko. O relato original, de 1917, foi interpolado por cartas de Manfred para a família e mais dois capítulos, escritos em 1918, sobre as suas impressões da recepção da obra pelo público germânico.

Os adendos escritos por Richthofen sobre a publicação da obra e a recepção do público leitor são muito ricos, inclusive pela questão da intenção autoral, que escapou do controle. Uma assertiva básica da crítica literária, a partir do estruturalismo do século XX, é que o texto sempre escapa às intenções do autor. O barão, chegando intuitivamente a essa percepção, reconheceu que talvez tivesse passado algo distorcido para o público. Ficou preocupado se os leitores foram expostos a outra pessoa, ao invés de quem ele realmente era. A leitura da obra pronta levou Richthofen a achar seu próprio discurso muito insolente, como se a guerra não fosse algo sério; segundo ele, era algo que não tencionou afirmar (RICHTHOFEN, 1933, p. 203-204).

O barão também percebeu que, se o texto escapou das intenções originais, os leitores produziram sentidos ainda mais diversos. Uma das cartas enviadas era de autoria de um leitor glutão, que pedia desesperadamente que Richthofen lhe 
indicasse onde poderia conseguir ostras: "vagamente me recordo de haver mencionado ostras, mas este honorável camarada tomou o problema das ostras como a quintessência do livro" (RICHTHOFEN, 1933, p. 199-202). Um estudante mandou um espelho de presente, ao concluir com a leitura que o barão precisava de um. Uma senhorita e uma freira escreveram que o idolatravam. Aquela já havia lido sete vezes Der rote Kampfflieger, essa chegou a colar uma foto do rosto de Richthofen num retrato de uma santa, para que a madre superiora não percebesse, pois obviamente era um comportamento que não condizia com as regras do convento.

O lançamento de Der rote Kampfflieger, no penúltimo ano da guerra - época de ânimos exaltados pelo nacionalismo e chauvinismo e também de temor pelas expectativas de um futuro incerto - provocou diversas reações no público germânico, além daquelas relatadas. Este livro foi o precursor de uma série de autobiografias de pilotos, que seriam publicadas ao longo do século XX. Poderíamos até arriscar a afirmar a existência de um gênero literário autônomo.

Mas essa obra não surgiu do nada. Imbricados no texto, existem, dentre outras, concepções aristocráticas e nacionalistas. Ao comentar a morte do ás britânico Albert Ball - supostamente abatido por Lothar von Richthofen, como afirmaram os germânicos, apesar do desmentido inglês - o barão perguntava-se como um "homem tão grande como ele [Ball]" (1933, p. 185), poderia ter uma morte normal. Um herói merece uma morte heróica, em combate; era a bela morte que Aquiles também almejava (VERNANT, 1992, p. 33-41). Era aos mortais comuns que estava destinada a morte 'feia', por velhice ou doença. Como indivíduo inserido na sociedade, Richthofen incorporou, consciente ou inconscientemente, alguns valores ao seu texto. Quais são esses valores e como são incorporados? Esta é uma pergunta que deve ser respondida pela pesquisa ulterior. No caso de Der rote Kampfflieger, Richthofen usou uma profusão de 'eus', que poderia indicar essa tentativa de aproximação com o leitor, ou uma tentativa de manter a individualidade perante o conflito ou então poderia ser o resultado de sua pouca aplicação nos estudos.

Richthofen passou a maior parte de sua breve vida - ele morreu poucas semanas antes de completar 26 anos - no meio militar. Primogênito de uma família aristocrática prussiana, ele ingressou na academia de cadetes aos 11 anos de idade. Essa decisão foi tomada pelo pai de Manfred, o major von Richthofen, sem consultá-lo. Esse evento não era nenhuma exceção para a aristocracia alemã. Era 
um aluno medíocre, aplicava-se apenas o suficiente para continuar na academia (KILDUFF, 1993, p. 24). O grande interesse do jovem estava nos esportes: futebol, ginástica, caça e corridas eqüestres (RICHTHOFEN, 1933, p. 27). Ao ingressar no exército como oficial, com o posto de leutnant ( $2^{\circ}$ tenente), foi designado para o $1^{\circ}$ regimento dos Ulanos. ${ }^{10}$ Só em 1915, com a guerra em andamento, Richthofen foi transferido para o serviço aéreo, primeiro como observador, mais tarde como piloto.

O ás alemão nunca perdeu o interesse pelos esportes. Nas folgas, ele quase sempre saía para caçar nas florestas. Essa atividade é correlata com a aviação de caça, pois ambas exigem espreita, sangue-frio e boa mira. Richthofen, revelando um lado passional, admitiu que, no momento em que tinha um alvo na mira, fosse um bisão selvagem ou um aviador britânico, ele era acometido da "febre da caçada" (RICHTHOFEN, 1933, p. 189). As emoções sob estrito controle, uma das características típicas da nobreza prussiana, eram substituídas pela sensação agonística de vencer o adversário, qualquer que fosse ele. Para descrever tal sensação, o barão teve que recorrer a uma metáfora. A febre faz o doente delirar e tremer, tirando-o de seu juízo perfeito. A competição é uma forma de combate e vice-versa. A guerra possui características inegavelmente lúdicas. O divertimento do jogo ${ }^{11}$ escapa a qualquer definição racional.

Procuramos, neste breve ensaio, tão somente explorar o potencial do documento autobiográfico, a partir de diversos enfoques, propiciados pela história intelectual e pela crítica literária. Uma pesquisa mais aprofundada, sobre os conceitos de heroísmo e honra dos pilotos de caça de 1914-1918, foi desenvolvida na nossa tese de doutoramento (ARGUELHES, 2008). A fonte demanda procedimentos que podem ser empregados, mas, em última instância, é o historiador que decide quais estratégias analíticas utilizar. Do mesmo modo também, é o historiador que escolhe o objeto e qual recorte terá esse objeto. A narração daquilo 'que aconteceu'

${ }^{10}$ Um dos muitos regimentos de cavalaria do exército alemão durante o Kaiserreich (RICHTHOFEN, 1933, p. 27-32).

${ }^{11}$ Divertimento do jogo (aardigheid) é uma expressão utilizada pelo historiador holandês Johan Huizinga para expressar a essência do ato de jogar ou brincar. Os seres brincam e jogam pelo simples fato de ser divertido. Não existe nenhuma explanação racional que possa abarcar essa categoria. Para uma discussão mais aprofundada sobre o jogo como elemento cultural e sobre o caráter lúdico da guerra, ver Johan Huizinga (1999, p. 03-85; p. 101-108). 
surge, mais uma vez, das escolhas pessoais do historiador. Estas escolhas são construídas, são elaboradas ao nível de poiésis.

\title{
The fighter pilots of Great War of 1914-18 and the return of knight's frays: brief notes on the autobiography of the Red Baron
}

\begin{abstract}
:
The present article inventories interpretative procedures, in the field of the history of the ideas, concerning the autobiography of the German pilot Manfred von Richthofen (1892-1918), as historical source concerning the conceptions of heroism, honor and chivalry of the fighter pilots in the Great War of 1914-1918.
\end{abstract}

Keywords: History of the ideas. History of World War One. Autobiographical narratives.

\section{Referências}

ARGUELHES, Delmo de Oliveira. Sob o céu das valquírias: as concepções de heroísmo e honra dos pilotos de caça na grande guerra (1914-18). Tese (Doutorado), Universidade de Brasília - UnB. Brasília, 2008.

BAKHTIN, Mikhail. Estética da criação verbal. 4. ed. São Paulo: M. Fontes, 2003.

EKSTEINS, Modris. A sagração da primavera: a grande guerra e o nascimento da era moderna. Rio de Janeiro: Rocco, 1991.

FRANTZEN, Allen J. Bloody good: chivalry, sacrifice and the Great War. Chicago: The University of Chicago Press, 2004.

FREUD, Sigmund. O mal estar na civilização. Rio de Janeiro: Imago, 1997.

GADAMER, Hans-Georg. Verdade e método I: traços fundamentais de uma hermenêutica filosófica. 5. ed. Petrópolis: Vozes, 1997.

GAY, Peter. Freud para historiadores. 2. ed. Rio de Janeiro: Paz e Terra, 1989.

GUSTON, Bill et al. The encyclopedia of air warfare. London: Salamander Books; Spring Books, 1975. 
HUIZINGA, Johan. Homo ludens: o jogo como elemento da cultura. 4. ed. São Paulo: Perspectiva, 1999.

JAUSS, Hans-Robert. A história da literatura como provocação à teoria literária. São Paulo: Ática, 1994.

. Pour une esthétique de la réception. Paris: Gallimard, 1978.

KILDUFF, Peter. Richthofen: beyond the legend of the Red Baron. New York: John Wiley and Sons, 1993.

KOSELLECK, Reinhart. Espaço de experiência e horizonte de expectativa: duas categorias históricas. In: FUTURO passado: contribuição à semântica dos tempos históricos. Rio de Janeiro: Contraponto; PUC Rio, 2006. p. 303-330.

. História dos conceitos e história social. In: FUTURO passado: contribuição à semântica dos tempos históricos. Rio de Janeiro: Contraponto; PUC Rio, 2006. p. 73-91.

. Uma história dos conceitos. Estudos históricos, Rio de Janeiro, n. 10, p. 134-146, 1991.

KUHN, Thomas S. A estrutura das revoluções científicas. 5. ed. São Paulo: Perspectiva, 1997.

LACAN, Jacques. O seminário - Livro 2: o eu na teoria de Freud e na técnica da psicanálise. Rio de Janeiro: J. Zahar, 1985.

. Escritos. Rio de Janeiro: J. Zahar, 1998.

POCOCK, John Grenville Agard. Politics, language and time. Ithaca: Cornell University Press, 1971.

. Linguagens do ideário político. São Paulo: Edusp, 2003.

RICHTHOFEN, Manfred von. Der rote Kampfflieger. Berlin: Verlag Ullstein, 1933.

RICOEUR, Paul. Indivíduo e identidade pessoal. In: INDIVÍDUO e poder. Lisboa: Edições 70, 1988.

SARLO, Beatriz. Tempo passado: cultura da memória e guinada subjetiva. São Paulo: Companhia das Letras; Belo Horizonte: UFMG, 2007. 
UDET, Ernst. Mein Fliegerleben. Berlin: Verlag Ullstein, 1937.

VERNANT, Jean-Pierre. 'A bela morte de Aquiles'. In: GAUTEHRON, Marie Gautheron (Org.). A honra: imagem de si ou dom de si - um ideal equívoco. Porto Alegre: L\&PM, 1992.

WINTER, Denis. The first of the few: fighter pilots of the First World War. Athens: The University of Georgia Press, 1983. 